\title{
Development of Urban Green Space Affects Neighbourhood Community Social Interaction
}

\author{
Mohd Hisyam Rasidi, Nurzuliza Jamirsah, Ismail Said \\ Department of Landscape Architecture, Faculty of Built Environment, \\ Universiti Teknologi Malaysia, Johor, Malaysia \\ ismailbinsaid@gmail.com
}

\begin{abstract}
While Malaysia is heading for urbanization, urban green space degradation had occurred. Malaysia's typical urban green space had shown the demotion of social interaction among urban residents. Hence, this research aimed to understand the designs of typical Malaysian green spaces which are believed to enhance community social interactions. Variables measured were the physical and natural characters of selected green spaces including activities, attractions and settings. The observation took place during representative of weekday, weekend and public holiday in those green spaces. The result suggested that diversity of subspaces including vegetation density, animal populations, undulating landforms and water bodies afford social interaction behavior.
\end{abstract}

Keywords: Social Interaction; Urban Dwellers; New Township Residential; Urban Green Space

eISSN 2514-751X @ 2018. The Authors. Published for AMER ABRA cE-Bs by e-International Publishing House, Ltd., UK. This is an open-access article under the CC BY-NC-ND license (http://creativecommons.org/licenses/by$n c-n d / 4.0 /$ ). Peer-review under responsibility of AMER (Association of Malaysian Environment-Behaviour Researchers), ABRA (Association of Behavioural Researchers on Asians) and cE-Bs (Centre for EnvironmentBehaviour Studies), Faculty of Architecture, Planning \& Surveying, Universiti Teknologi MARA, Malaysia. https://doi.org/10.21834/aje-bs.v3i8.281 


\subsection{Introduction}

This paper aimed to discover the green space design characteristics which could contribute to the factors affecting level of social interaction among new township residents in Malaysia. This paper reveals the design characteristics of green space which eventually promote or hinder social interaction. Objectives of this paper area) to identify the design characteristics of green space that could promote social interaction; and b) to identify the activities that could unite people. Urban green spaces are essential component in new townships due to the opportunities they provide for people to come in contact with each other. In terms of social well-being, urban green space has the potential in reducing negative social behaviour such as aggression and violence, thus contributing to a sense of place and harmony, and hence plays an important role in fostering social cohesion and social identity (Dempsey, Brown, \& Bramley, 2012).

\subsection{Literature Review}

Many studies confirmed the urban residents' had tendencies of preferences for urban areas with green spaces in and around them (Bell et al., 2008; James etal., 2009). Proximity to green space is associated with increased use of the space. The design character of urban green spaces is a significant factor in promoting activities for urban society, thus changing human behavioural patterns and cultural norms among urban communities. Strong social ties within the urban community could foster an environment that associated with connectedness, meaning, and purpose, whereas lack of integration may contribute to feelings of hopelessness, thus increasing the risk of depressive symptoms (Abada et al., 2007). A sense of interaction among urban residents provides an opportunity to get to know their neighbourhoods and as well as their friends in the area.

Prior research demonstrates urban green spaces could be inclusive spaces. They could be seen as possibly favourable spaces for stimulating social interaction. However, modern community these days does nothave many intensive social interactions with strangers. Most of them feel comfortable communicating only within their own social group and do not feel the need to interact with others. This is in line with earlier research (Lofland, 1998) which concluded that interactions with unknown people are less typical than those with known ones. Most people like to be in these green spaces and enjoy meeting and seeing other people, which could lead to the feelings of connection to the place and strong community cohesion (Peters et al., 2010).

However, not all people would go to the green spaces to engage with others. Sometimes they just need a privacy space for themselves. These kinds of people enjoyed observing others from afar. Lawson (2001) postulate that people and their social groups in urban area need to be approximately $4 \mathrm{~m}$ away from others in order to achieve self-comfortable zone and be able to ignore the existence of others within the same environment. In addition, at approximately $24 \mathrm{~m}$ and up to $60 \mathrm{~m}$ of distance has been defined as the limit for facial recognition zone (Thiel, 1997). Thus, regular visits to the green spaces can brought together familiar strangers to become friends.

Moreover, as long as the presence of others is enjoyed by oneself, the comfortable 
distance between them could be ignored. Urban green space provided the enclaves and sub-spaces in which users could use for having private moments, gathering activities or observing others from afar. Hence, urban green spaces are important because it represents as spaces in which could promote different ethnic groups mingling and communicating (Nurzuliza, 2012). It could be as a space where informal and cursory interactions occurred in order to feel connected. Insights into the green space characteristic are crucial for understanding the extent to which these places could facilitate social interaction. Urban green spaces that function as everyday places could be the places in which people feel at home.

\subsection{Definition}

Urban green space is defined as any piece of land covered by vegetation and often referred to as parks, golf courses, sports field and other open spaces within urban built-up area whether publicly accessible or not. Green spaces frequently comprises of all natural and manmade networks of multifunctional ecological systems within, around and between urban and semi-urban green spaces (Tzoulas et al., 2007). Green spaces could be considered as public or private space. Meaning private spaces are meant only for specific users and public spaces were meant for all types of users. In other words, notall green spaces are accessible by public users depending on its developer's rules and condition. For instance, green spaces that were owned by public authorities frequently considered as public amenities. In contrast with green spaces developed by private owners usually were not accessible to all but sometimes allowed public access. Green spaces could be categorized into a) parks and gardens; b) natural and semi-natural spaces;

c) green corridors; d) outdoor sports facilities; e) amenity green spaces; f) provision for children and young people; g) allotments, community gardens and urban farms; h) cemeteries, disused churchyards and other burial grounds; and i) public space (Bell et al., 2007). However, this research is focusing only on the urban park typology.

On the other hand, social interaction evidently could unite and harmonizes community in neighbourhoods. The term 'social interaction' in this research is defined as the bonds or relationship between two or more individual in a community, particularly in the context of multi-cultural diversity. It is also described as one's degree of connectedness and solidarity to one's community (Mahasin \& Roux, 2010). This paper reveals whether physical or natural characters of the green space design that could influence social interaction. It has been proven that the sense of centrality of spaces, user-centric design and existence of service and facilities, such as shops and service locations, are directly influencing people's presence in such spaces (Golicnik \& Ward Thompson, 2010). By acknowledging the importance of people socializing and contacting each other, this research is crucial in order to improve the green space functional design as well as improving human wellbeing.

\subsection{Issues of 'Shrinking Green'}

There is an increasing trend of research regarding on significance of green spaces. The development explosion of recent decades resulting in the loss of forest, farm, forest fringe, and other open space lands that somehow contributes to urban residents' quality of life. The growing scarcity of green space is at concern of local authorities nowadays since there are 
not much of quality green areas left. It is partly because the current condition of common urban green space was poorly design and eventually does not promote social interaction among urban residents (Nurzuliza, 2012).

Concurrently, Malaysia is developing towards urban and suburban landscapes, hence maintaining quality of existing green spaces or creating new green spaces needs a lot of attention in ensuring those green spaces are fully utilized and not abandoned as wasted space. However, some factors that may discourage people to use thus may hinders social interaction is the unattractive green space design. Some of the reasons residents do not use the green space is because they are not interested (Moore, 2003), not attractive, personal feelings of insecurity towards green space (Jorgensen \& Anthopoulou, 2007) and fear of crime. That is why a detail investigation on green space design should be carried out to prevent those negative notions.

\subsection{Methodology}

\subsection{Variables Measured}

This research explores urban residents' responses according to their social preferences and experiences within green spaces especially their relationship with green space design components. The design of the spatial configuration could serves as platform for social bonding and interaction. In order to comprehend design qualities that encourages social mingling it is recommended to measure the green space properties (i.e. green quality, green setting, accessibility, dynamic feature) and social attributes (i.e. personal information, social division and social preference) of the green space through documented responses (see Table 1). The unit of analysis is the various range of age group of new township residents in Johor Bahru. The reason of selecting them is because they function as representative of typical new township inhabitants in Malaysia. The approach in dividing the variables into two major categories were for collecting data systematically and to see how daily usage pattern of public green space was related to the spatial design arrangement. It is presumed that green space design complexity could attract more people coming to those green spaces (Nurzuliza et al.,2010).

Table 1: Variables being Measured are Classified into Independent (Green Space Properties) and Dependant (Social Attributes) Variables

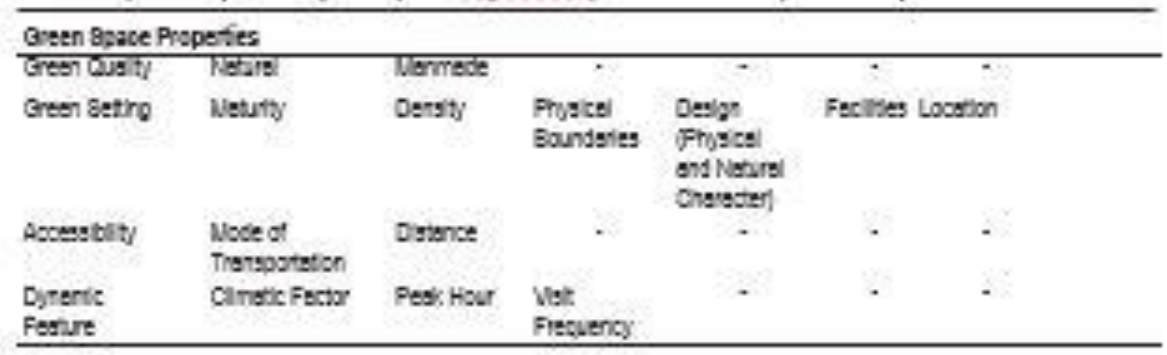




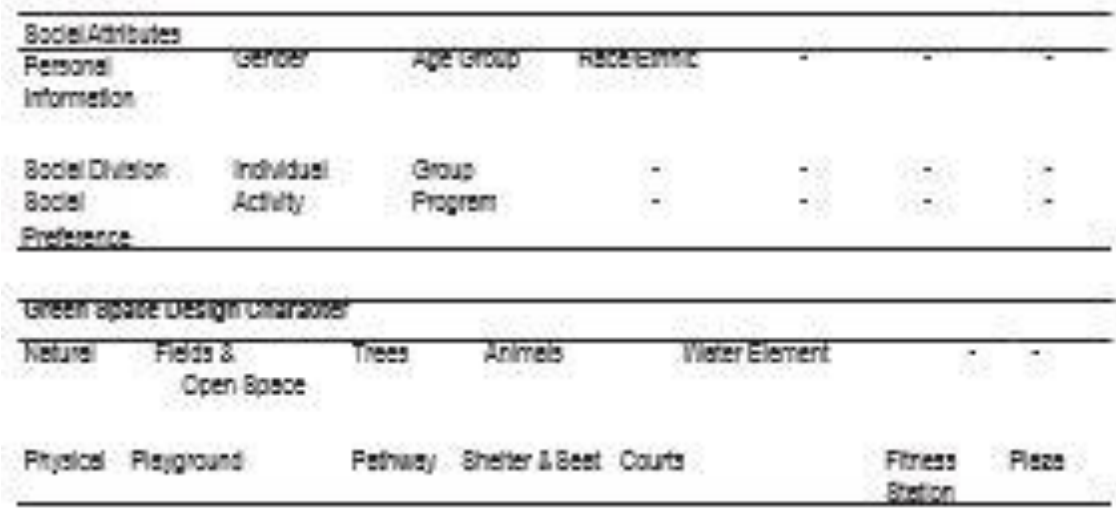

\subsection{Methods}

A total of 330 samples of survey questionnaires (SQ) were distributed within the selected green spaces. It was distributed randomly regardless the users' age, race and ethnicity. However, only 172 reliablerespondents were taken for further analysis due to the other 158 respondents left the questionnaires blank almost half out of total 27 questions. It is inevitable for questions to be unanswered. However the consideration taken into selection criteria for valid survey questionnaires were if the answered questions more than $50 \%$ out of total questions, the $S Q$ were still valid for further analysis. The unanswered questions can be consideredasincomprehensible, undecided, choiceless, unsure, unknown, confused, missed out, or ignored.

Then, green inventories of each site were carried out to map the spaces and characteristics each of the green space. It has been noticed that there are slight different and dissimilar uses observed in the green space usage of similar physical or natural characteristics within the green space. To ensure the spontaneous behaviour is recorded, unobtrusive observations were performed to map and generate behavioural movement patterns of users within those green spaces and a comparative analysis between both parks was performed. All of the sub-spaces of each of the green space were observed during each of these periods for three consecutive days of weekday, weekend, and public holiday. The time periods of the observation were chosen to capture the different usage patterns at different times of day and on different days of the week. There were four time periods taken for observation: 6-9 am; 9 am - 12 noon; $12-3$ pm and 3-6 pm. The observation techniques involved systematic walks and 10 minutes pauses for visual scan through each green space sub-areas. All noted users in that visual scan were recorded as 'point' on the green space master plan as indicated in Fig. 3 and Fig. 5. The micro climate condition such as weather and temperature were also recorded.

\subsubsection{Selected Green Spaces}

The green spaces selected for the investigation were Bukit Indah Town Park (BITP) and Mutiara Rini Urban Forest (MRUF). As shown in Fig. 1 and Fig. 2, both of the green spaces are situated 
and surrounded by mass housing development of new townships and are chosen out of the similar comparable size, green density and design character which represents the frequent usage by users. Comparative analyses were made with the two green spaces. The analyses were based on the year of establishment, dissimilar design characteristics, and users' visit frequencies. It is anticipated that frequent visits by users could contribute to higher level of social interaction regardless of the green space distance and aesthetic values. Hence, both of urban green spaces chosen are appropriate for investigating the behavioural responses of its users towards the designed properties of the green areas.

\subsubsection{Bukit Indah Town Park}

BITP has been established and built by the property developer SP Setia Bhd Group and first launched 16 years ago. This town park is part of Setia Indah Township which is a surrounded with matured and lush greeneries. It also composed with comprehensive park facilities and green infrastructure. This township encourages communal activities and promoting the importance of greeneries in everyday life. Since its emergence, the BITP has become a place for its urban residents to relief stress and experience the greens. This green space offers seats and shelters, resting areas, a plaza and children's playground. Recently, by the demands of its users and increased in popularity, BITP were upgraded to have more park facilities.

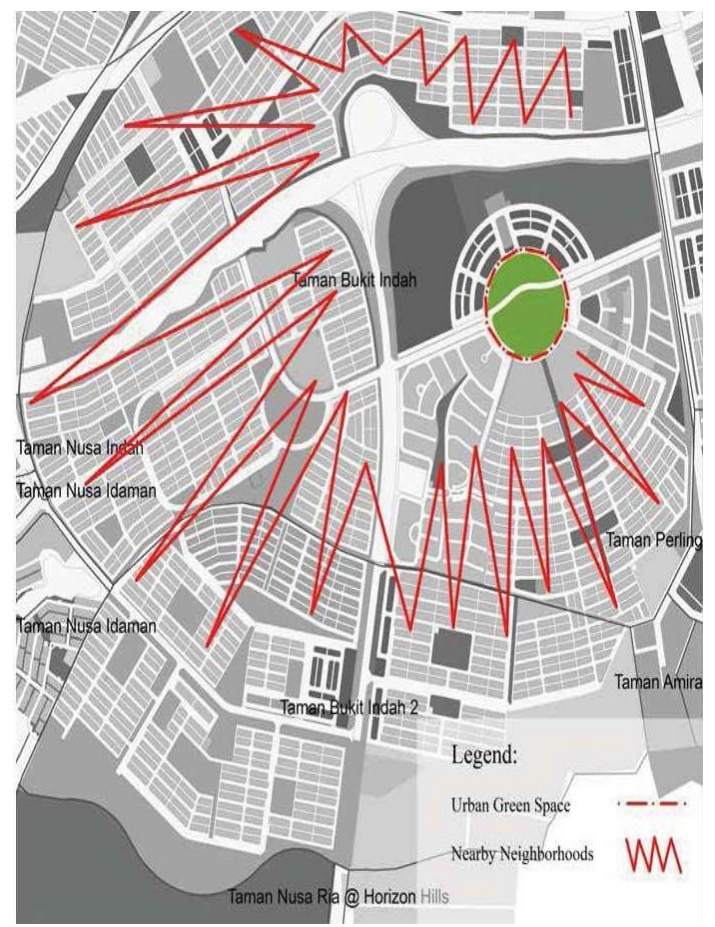

Figure 1: Bukit Indah Town Park (BITP) is Situated at the Midst of Residential Neighbourhoods and Commercial Areas 


\subsubsection{Mutiara Rini Urban Forest}

MRUF has been newly established for just about 3 years ago. It is located within the Mutiara Rini Township and was developed by Mutiara Rini Sdn Bhd. This urban forest consist of fruit trees, indigenous forest trees, palms, shrubs and manmade lake, in which to portray a forest like area that will become habitats for greater range of wildlife including migratory birds, fishes and animals. In order to preserve this green area, MRUF's developer has signed a Memorandum of Understanding in June 1996 with local authorities (MPJBT) and Forest Research Institute of Malaysia (FRIM) before developing this 64 acre of MRUF. MRUF provided recreational facilities within the sub-spaces, e.g. jogging tracks, children's playgrounds, camping sites, picnic area and rock climbing area. MRUF is slowly attracting people to visit and recognize its forest like experience hence, gaining its popularity among proximity urban residents.

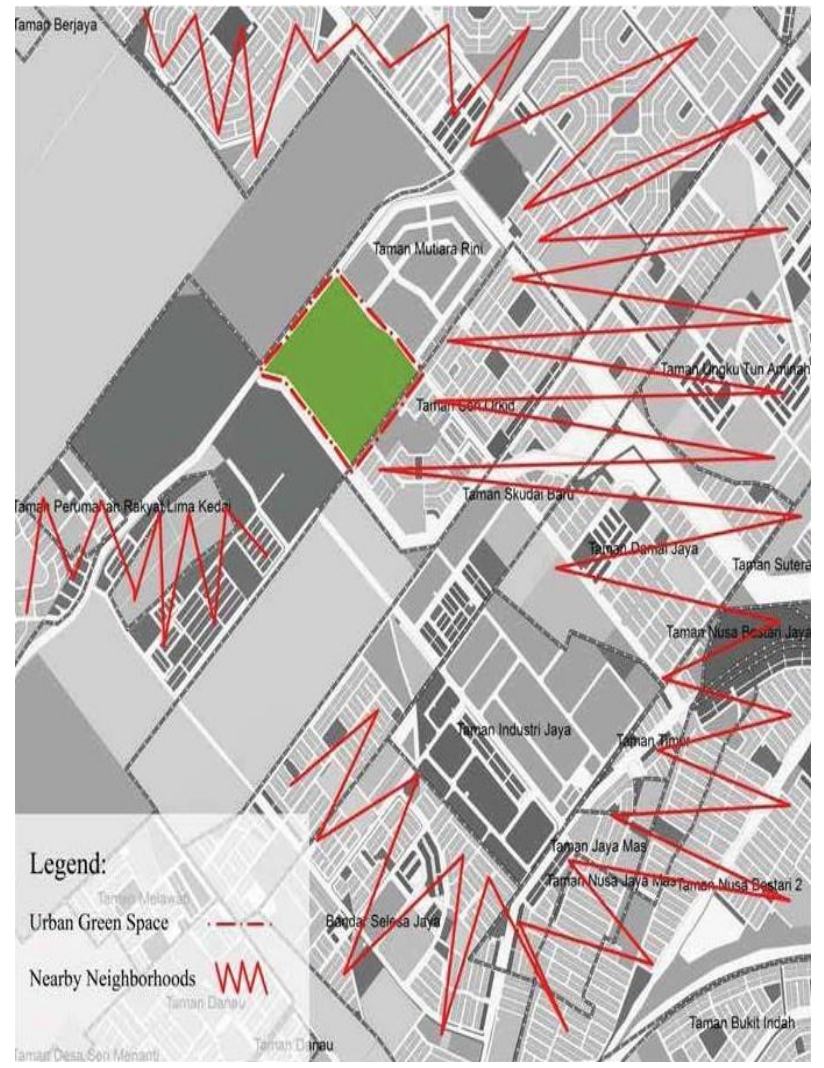

Figure 2: Mutiara Rini Urban Forest (MRUF) and its Broader Spatial Context of Residential Neighbourhoods 


\subsection{Findings and Discussion}

The data from survey questionnaires were coded into SPSS software for descriptive statistical analysis, e.g. the production of histograms, cross tabulation and correlation analysis. The main focused of this analysis was to understand the relationship between spatial arrangement and users' usage pattern. However, the additional attributes such as users' gender, race, age group, seniority in neighbourhood and home distance to green space were also considered to give additional information of the relationship. Descriptive analysis in Table 2 gives an overview on number of users involved in activities according to specified days for both of the green spaces.

Table 2: Descriptive Findings of Personal Information and Number of Respondents Involved in Activities Related to Green Space Designs

\begin{tabular}{|c|c|c|c|c|c|c|c|c|c|c|}
\hline \multirow{3}{*}{$\begin{array}{l}\text { Deaciptine } \\
\text { Culagain }\end{array}$} & \multirow{3}{*}{$\begin{array}{l}\text { Rodran } \\
\text { Varablea } \\
\text { Yeason: }\end{array}$} & \multicolumn{5}{|c|}{$\begin{array}{c}\text { Bulane Boulrter } \\
\text { Povat }\end{array}$} & \multicolumn{4}{|c|}{ Dabi intat Tewn Pare. } \\
\hline & & \multicolumn{4}{|c|}{ Gender } & $N=74$ & \multicolumn{3}{|c|}{ Gender } & \multirow{2}{*}{$\begin{array}{c}k \rightarrow 2 \\
5\end{array}$} \\
\hline & & & \multicolumn{3}{|c|}{ Correstels all } & $\mathrm{s}$ & \multirow{2}{*}{$\begin{array}{c}\text { Pernale } \\
\text { \& }\end{array}$} & \multicolumn{2}{|c|}{ Ian al } & \\
\hline Fwaona! & Aae grous & Astolusem! & 20 & 14 & 24 & 48 & & 20 & 28 & 27 \\
\hline \multirow[t]{23}{*}{ Irle } & & Asul: & 20 & 10 & 40 & $\mathbf{s}$ & 28 & 28 & 72 & 74 \\
\hline & Rece & Maluy & 20 & 17 & 48 & 82 & $2 !$ & 27 & 42 & $4:$ \\
\hline & & Chi-wat & $:$ & $I$ & 12 & 18 & 10 & 28 & 28 & 28 \\
\hline & & Indixy & 11 & 1 & 14 & 18 & : & 5 & 13 & 12 \\
\hline & & Dthar & 1 & 1 & 2 & J & 2 & 2 & 2 & 5 \\
\hline & 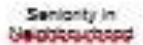 & Few mant-a & 2 & 1 & 6 & 8 & \pm & 5 & 11 & 11 \\
\hline & & A-2 yaura & 2 & 0 & 5 & 7 & : & : & 18 & 18 \\
\hline & & $4-7$ yaura & 17 & 1 & 20 & $2 \pi$ & 8 & 18 & 28 & 2s: \\
\hline & & $\begin{array}{c}\text { Mere fren } t \\
\text { yasra }\end{array}$ & 28 & 12 & 43 & 58 & 18 & 27 & 48 & $4 t$ \\
\hline & Cangenian & $F=-l y$ & 43 & 12 & 8 & 78 & it & 22 & 40 & 90 \\
\hline & & $\begin{array}{l}\text { Peor and } \\
\text { Arienda }\end{array}$ & $?$ & 11 & 18 & 24 & 12 & 22 & 28 & 27 \\
\hline & & Alane & & & & & 5 & 8 & 3 & $:$ \\
\hline & Na of Mambarz & i pouen & I & 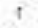 & $i$ & 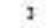 & 2 & 12 & 15 & 15 \\
\hline & & 2-5 seruen & 23 & 18 & 40 & 88 & 12 & 20 & 71 & 72 \\
\hline & & 6-7 geraon. & 11 & 4 & 15 & 20 & 5 & 2 & 7 & 7 \\
\hline & & In groupa & 9 & $I$ & 8 & 14 & 2 & 2 & 2 & 5 \\
\hline & $\begin{array}{l}\text { Interasien } \\
\text { Timeireme }\end{array}$ & $9.10 \mathrm{~min}$ & ve & 8 & 25 & 34 & 17 & 17 & 28 & 31 \\
\hline & & $10-30 \mathrm{~min}$ & 94 & 4 & 18 & 24 & 2 & 18 & 27 & 28 \\
\hline & & $\begin{array}{c}\text { Mere fren } 1 \\
\text { nou? }\end{array}$ & 20 & 11 & 31 & 42 & 14 & 21 & 25 & 18 \\
\hline & $\begin{array}{c}\text { Wat } \\
\text { Freouerney }\end{array}$ & Every manth & 13 & e & 19 & 20 & 8 & 4 & 13 & 13 \\
\hline & & $\begin{array}{l}\text { Thise a } \\
\text { manth }\end{array}$ & 20 & e & 20 & 25 & 12 & 14 & 28 & 27 \\
\hline & & Gvery nuak & 14 & t & 22 & 20 & $\because$ & 27 & 45 & 48 \\
\hline & & Everydey & 2 & 4 & $T$ & 3 & 2 & T1 & 14 & 14 \\
\hline \multirow[t]{6}{*}{ Astintex } & Gxcerdas Play & Aores & 28 & 14 & 42 & T & 14 & 12 & 47 & 48 \\
\hline & Family & Agrea & 24 & ; & 20 & 44 & 19 & 27 & 42 & 42 \\
\hline & Cunts-D & Neutra & 21 & 7 & 28 & 28 & 18 & 28 & 44 & 45 \\
\hline & Dase & Neutre: & 23 & 8 & 32 & 42 & it & 28 & 48 & 90 \\
\hline & Pnsts-Triking & Aaren & 13 & 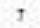 & 22 & 20 & 18 & 28 & 47 & 48 \\
\hline & Werking & Neutre: & 20 & 10 & 20 & 44 & 19 & 22 & 28 & 20 \\
\hline \multirow[t]{4}{*}{ Adretiona } & $\begin{array}{l}\text { Fieda end } \\
\text { Doun Sgasa }\end{array}$ & foren & 24 & 14 & 28 & $\$ 1$ & 14 & 28 & 42 & 42 \\
\hline & Treas & Aares & 22 & 7 & 22 & 42 & 17 & 97 & 24 & 15 \\
\hline & Aninal & Neutra: & 20 & 10 & 20 & 41 & is & 27 & $\leq x$ & 34 \\
\hline & Pleyaround & Agres & 22 & ? & 40 & 94 & 12 & 22 & 25 & 18 \\
\hline
\end{tabular}




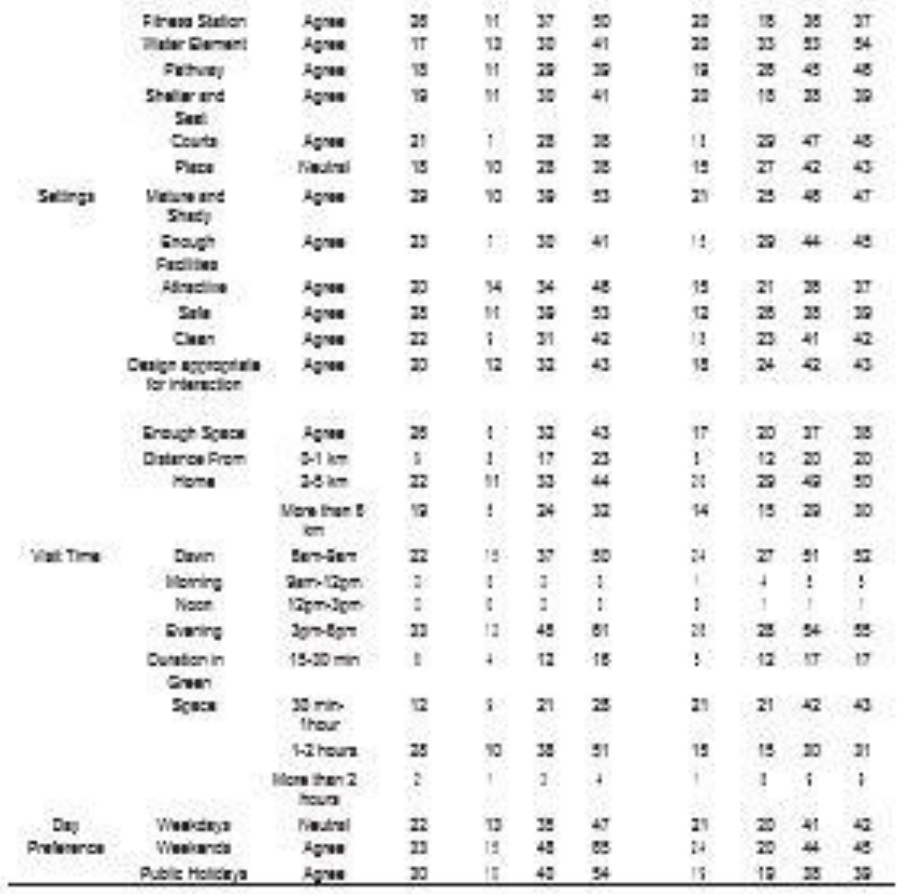

Based on Table 2, the notion of Agree, Neutral and Disagree were to differentiate respondents' understanding of the questions. Agree represents the users had understood the question and consented. Neutral represents the users thought of the question was as incomprehensible, undecided, choiceless, unsure, unknown, confused, missed out, or ignored. As for Disagree it represents the users had understood the question and disapproved.

\subsection{Composite Behavioural Mapping}

The data collected from each behavioural observation, originally mapped by hand, was later translated into digital form.

As shown in Figure 3, 'point' symbols were documented on the map to show favourite spots of the respondents. It is also showing the location of where the survey questionnaires were distributed. This method is conducted by two research assistants to document unbiased spot observation. These information were later layered to compose a composite behavioural map for each of the green space selected. The empirical findings about usage-spatial relationships based on the selected green spaces are discussed on the basis of overlapping composite maps combining several observations at different times during the survey period (see Figures 3 and 5). These composite maps of behaviour show grouping and collective patterns across the case studies. Even if the daily and composite maps of behaviour were 
presented separately, the results would still reveal some similar usage patterns. These analyses were taken under the same circumstances of the usage on different days, time periods and micro climate condition. By focusing on some significant patterns in relation to green space spatial characteristics, the following observations were made to see the influence of spatial designs to users' occupancy.

\subsection{BITP Composite Behavioural Map}

BITP is composed of playgrounds, a basketball court, several sheltersand seats, lawns, looping walkway, and large scale art piece of a pyramid steel structure. BITP is adored by its greenness maturities which are continue growing spectacularly through these years. Due to high demands from proximity residential users, this park had been upgraded on year 2012. Most of the vegetation was forest species such as Alstonia angustiloba and Tabebui rosea. This park is regularly maintained by the owner for the conducive usage of its nearby residential users. The size of this town park is about 21 acres.

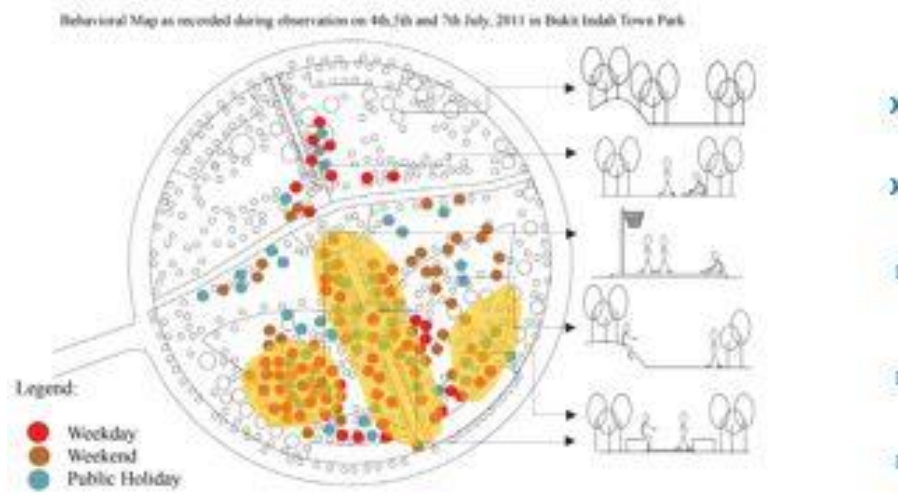

Figure 3: Favourite Spots of BITP Users. The Most Favoured Space are the Basketball Court, Less Dense Vegetation with Undulating Surface and Seating Under Shady Trees. The Least Favoured Space is the Area with Dense Vegetation and Flat Landforms

Different green space characters and spatial qualities promote various activities including active or passive. Activities such as playing, walking or sitting on the grass, are the typical examples of evidence represented on this behavioural map for BITP. Based on the map, the findings show that most people like to stay on paved surfaces and under shadows of tall figure such as seats under the shady trees. Paved surface shows that people do not like to get dirt on them and shady trees shows they need a cool space to have an activity. The second favoured space was the basketball court. It is because that basketball court is the only play court available at proximity distance to the residential areas. It is noticed that same adolescents group were occupying the play court every evening. This findings show that they needed more of this play court element to support their active activities. The third favoured space was the less dense vegetated area with undulating landforms. This findings shows 
people still enjoy the company of nature. However, it is only limited to the well maintained or trimmed greeneries with no possible harmful animals hidden within. A clear and visible path to walk on makes people feel secure that there are no unseen inhabitants crawling underneath. As for the least favoured space was the dense vegetated area. This findings shows some people have the fear of unseen inhabitants of multi-layered vegetated area. The unseen animals usually are dangerous or poisonous such as snakes make people want to avoid such spaces.
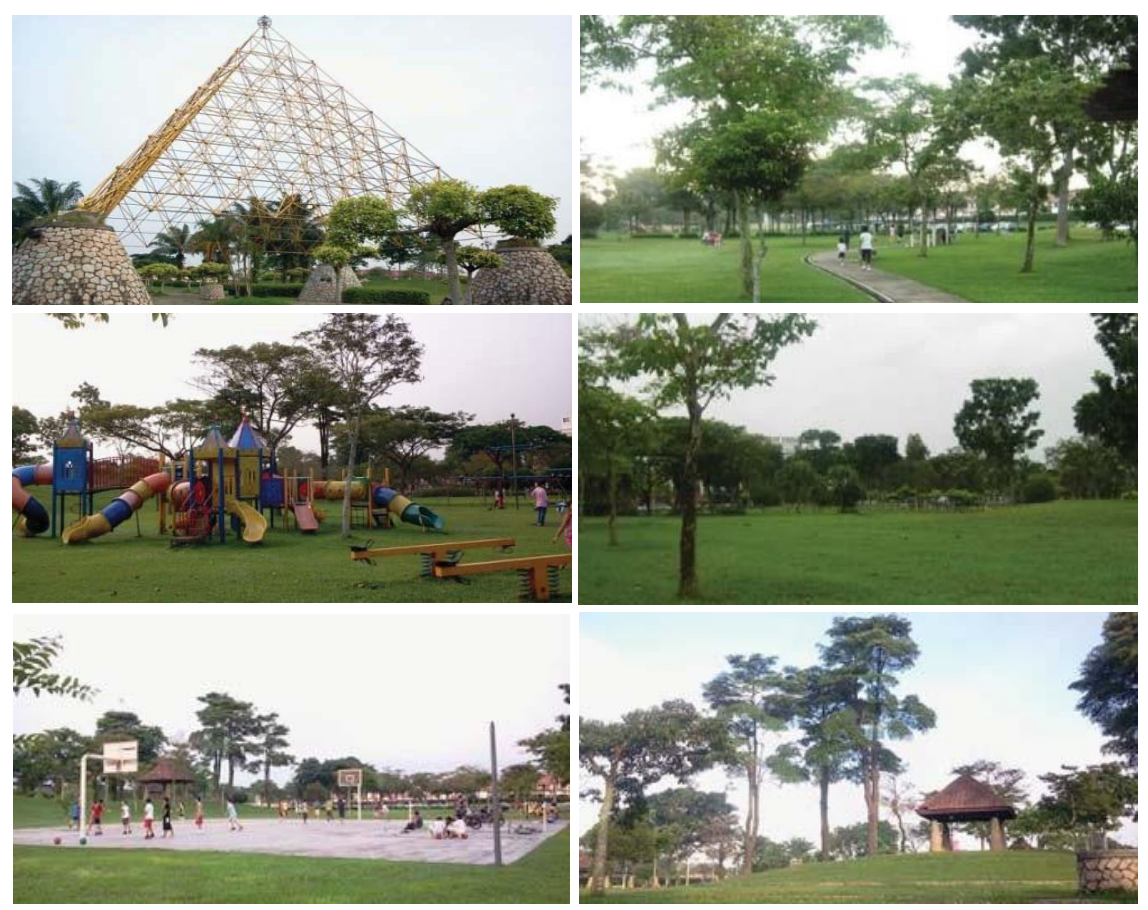

Figure 4: Green Space Quality and Typical Usage of BITP

\subsection{MRUF Composite Behavioural Map}

MRUF is composed of variety complex playgrounds, play fields, several shelters and seats, lawns, looping walkway, parcourse stations, and a manmade lake. MRUF is adored by its diverse park facilities and amenities. MRUF is developed by phasing stage. Currently, this park is constructing its second phase of enlarging the park and adding more park facilities to suit users' needs. Most of the vegetation was to replicate forest species as Alstonia angustiloba, Hopea odorata and Dipterocarp sp. This park is regularly maintained by the MPJBT for the conducive usage of its users. The overall size of MRUF was 64 acres. However, only 40 acreswere developed as the current park and another 24 acres reserved for research 
ground for Forest Research Institute Malaysia (FRIM).

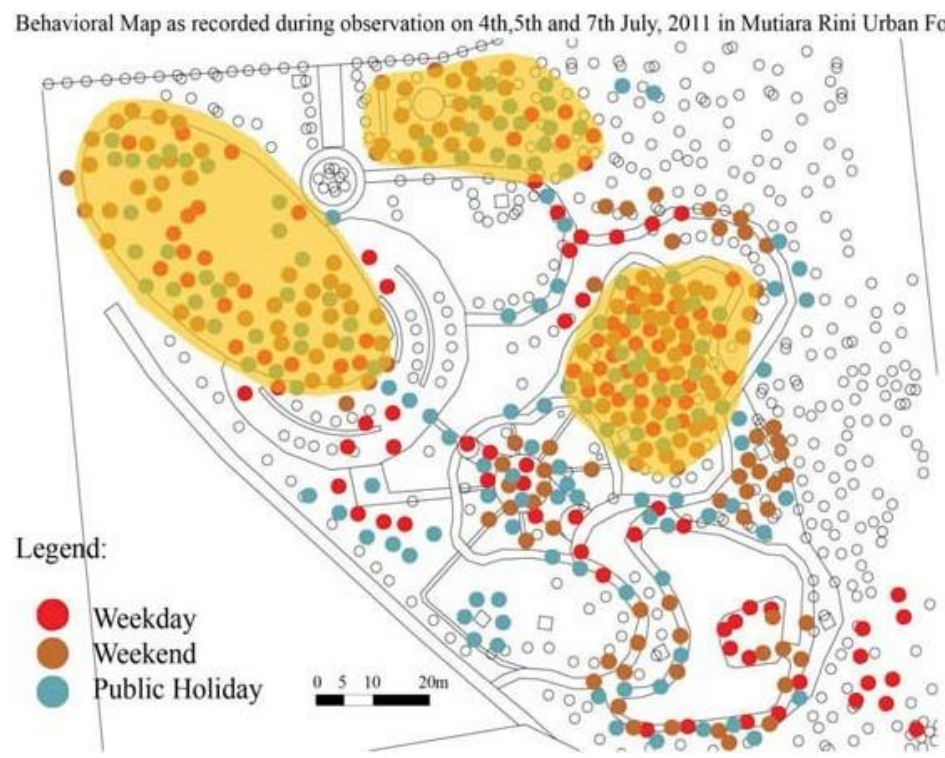

Figure 5: Favourite Spots of MRUF Users. The Most Favoured Space are the Complex Play Equipments of the Playgrounds, Windy Play Field for Kite-Playing and Pathways for Cycling and Jogging. The Least

\subsection{Favoured Space is the Area with Dense Vegetation and Manmade Lake}

Similar to BITP, activities such as playing, walking and sitting too are the daily usage pattern of MRUF. Based on the map, the findings show that most people come to this green space favoured the playgrounds. The different types of playground complexity attract parents and children to visit this green space. The playgrounds became a provisional space for parents to do other activities while their children occupied with the play equipments. The second favoured space was the windy play fields. One of the reasons the field is windy is due to the low rise adjacent development. This wind factor promotes users to play kites. Kites kiosk suddenly exists to support the users' kite-flying activities. These findings shows people are intrigued and attracted by unique characteristics or events such as complex playgrounds and kite-flying. To possess some physical or natural character in which other green spaces do not have can be a key factor to attract users. The third favoured element was the $6 \mathrm{~m}$ pathway in which can be occupied for cycling, jogging or skate-boarding activities at once. This finding shows people like to perform their own activities in the green space as long as they are not bothering or been bothered by others. As for the least favoured space was the dense vegetated area. This findings shows similar result with BITP which is some people has the fear of unseen harmful inhabitants of multi- layered vegetated area. Another least favoured space 
wasthe manmadelake. The possible reasons were the unpleasant odour or silty water of the lake.
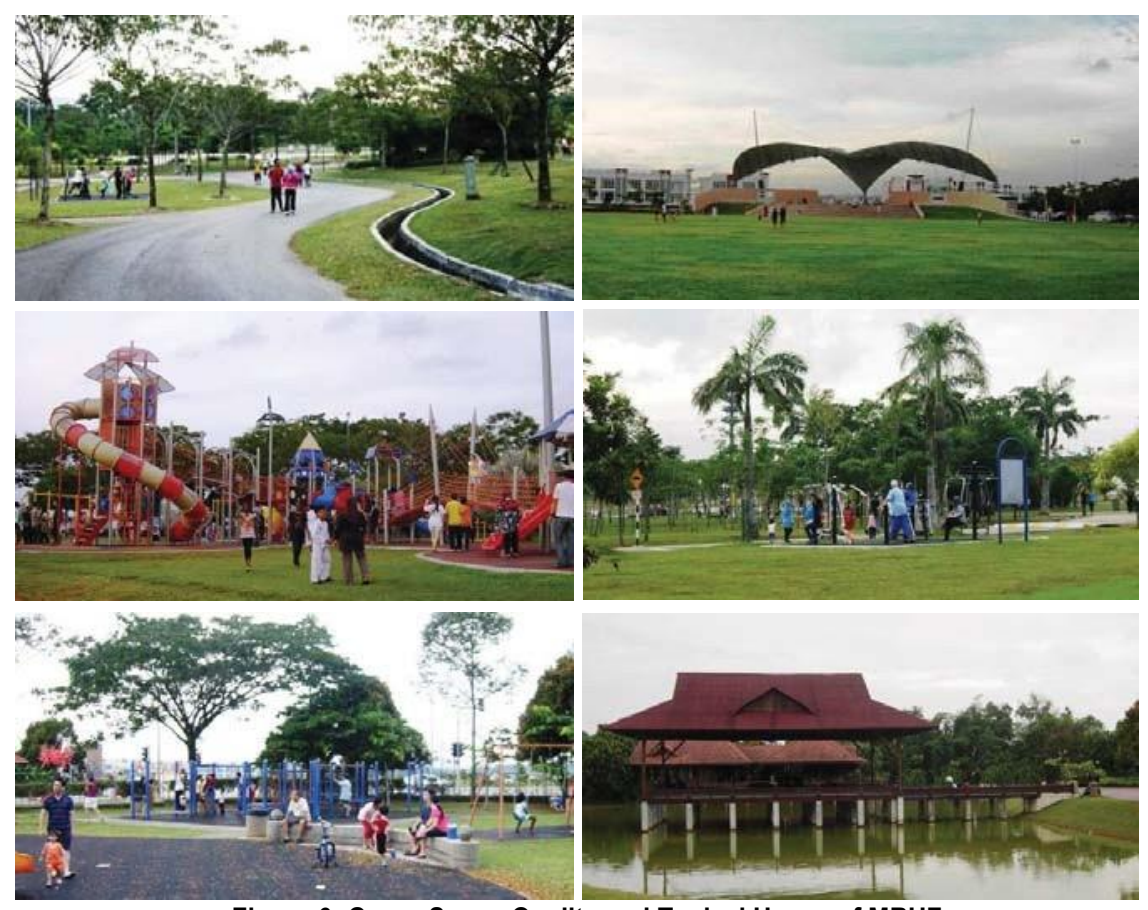

Figure 6: Green Space Quality and Typical Usage of MRUF

\subsection{Structural equation modelling}

Structural equation modelling aims at quantifying the strength of causal relationships within a set of interacting variables. In order to make the evidence more empirical, data coded in SPSS were linked to AMOS software to perform Structural Equation Modelling (SEM). By using SEM, a simultaneous model of inter-relationships between green space design components and its affordance for activity could be estimated. This research has constructed two models without any feed-back loop (see Figures 6 and 7), which means in SEM terminology as "recursive models" because they can be solved "recursively".

Each model contained exogenous (independent) and endogenous (dependant) variables which includes the direct and indirect effects of one variable on another. Both of the models are reliable due to their $p$ value $<0.002$ and 0.023 using the significant difference in reliability (Bonferroni corrected $p<0.05$ ); *significant difference in validity (Bonferroni corrected $p<0.05)$. However, at least for sample sizes of 172 or more, it also demonstrates that the accuracy of relative strength of coefficients is retained about $90 \%$ of the time when the initial covariance matrix leads to a solution. The following explanation is for both cases of 
covariance matrices leading to improper solutions.

\section{Reliability and Validity}

To reach the goodness of fit several indices should be considered. The first index referred was $\mathrm{CMIN}$, which is actually the likelihood ratio Chi Square $(\mathrm{CMIN} / d f=<2-5)$. The next indices are NFI (normed fit index) and CFI (comparative fit index). For these indices, the values close to 1 are generally considered to indicate a good fit (NFI $=>0.8-1.0$ and $\mathrm{CFI}=>0.9-1.0$ ) (Arbuckle, 2010). The NFI and CFI is an example of descriptive Bt index and indicates the proportion of improvement of overall fit of the model relative to the independence model only the CFI may be less affected by sample size. RMSEA is one of the indices that are frequently referred to. RMSEA (root mean square error of approximation) function to evaluate to the extent if a model fails to fit the data per degree of freedom, suitable for complex models. It is considered as a bad fit if the RMSEA value is greater than 0.08 (Byrne, 2010).

\subsubsection{Model A of BITP}

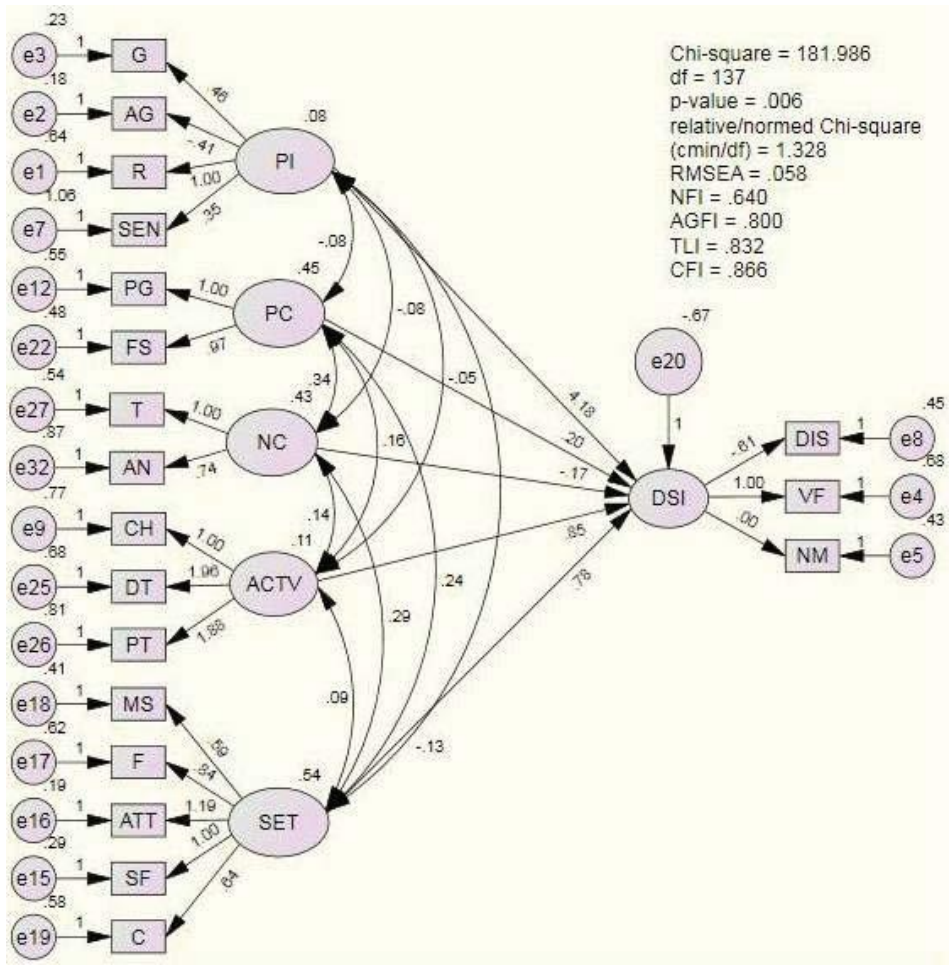

Figure 7: Structural Equation Model A for BITP. DSI=Degree of Social Interaction, PI=Personal Information, $\mathrm{PC}=$ Physical Character, $\mathrm{NC}=$ Natural Character, $\mathrm{ACTV}=\mathrm{Activities}$, and $\mathrm{SET}=$ Green Space Settings 
As for Model A (see Figure 6), the model shows a good fit with indices $C M I N / d f=1.33$, $p=0.006, \mathrm{NFI}=0.64, \mathrm{CFI}=0.87$, and RMSEA $=0.06$. From the model, the most significant values for measured variables are the $\mathrm{PI}$ (personal information) $=4.18$, followed by ACTV (activities) $=0.85$ and SET (green space setting) $=0.78$ respectively. It can be concluded that respondents came to the park due to the dominant factor of PI which are the $G$ (gender), AG (age group) and R (race). The sub-variables of ACTV which are affecting the DSI are the $\mathrm{CH}$ (chatting), DT (dating) and PT (photo taking). As for the SET sub-variables which also influencing the DSI are the MS (green space maturity and shadiness), F (facilities), ATT (attraction), SF (safety) and C (cleanliness). Other sub-variables that may influence the DSI (degree of social interaction) are the VF (visit frequency), NM (no. of member broughttogreen space), and DIS (green space distance from home).

\subsubsection{Model B of MRUF}

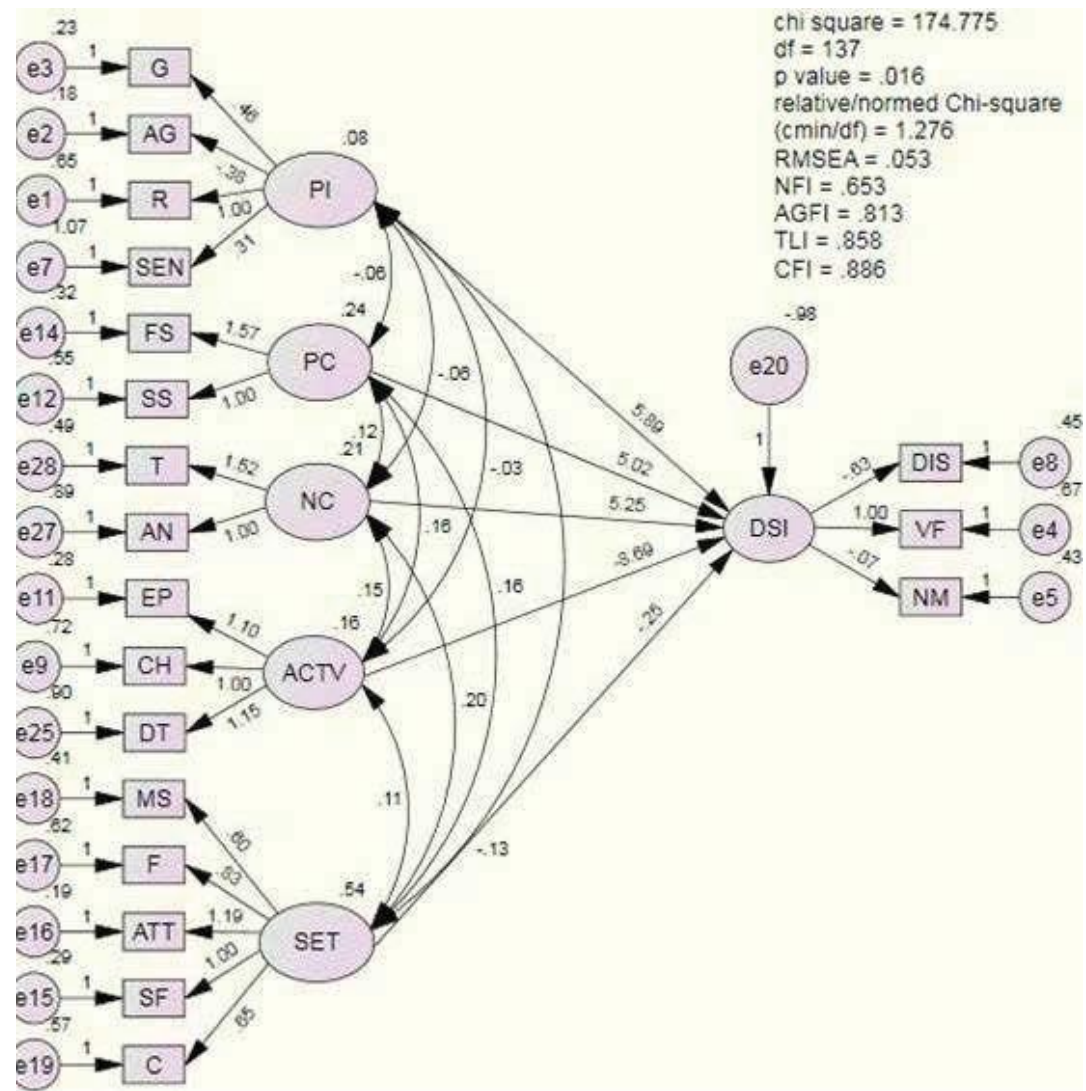

Figure 8: Structural Equation Model B for MRUF. DSI=Degree of Social In- teraction, $S E T=G r e e n$ Space Settings, $\mathrm{PC}=$ Physical Character, $\mathrm{NC}=$ Natural Character, $\mathrm{ACTV}=$ Activities 
As for Model $B$ (see Figure 7), the model shows a fair fit with indices $C M I N / d f=1.28, p=$ $0.016, \mathrm{NFI}=0.65, \mathrm{CFI}=0.89$, and RMSEA $=0.05$. From the model, the most significant values for measured variables are the ACTV (activities) $=8.69$, followed by PI (personal information)= 5.89 and NC (natural character) $=5.25$ respectively. It can be concluded that respondents came to the park due to the dominant factor of ACTV which are the EP (exercise and play), $\mathrm{CH}$ (chatting) and DT (dating). The sub-variables of PI which are affecting the DSI are the $G$ (gender), AG (age group) and R (race). As for the NC sub-variables which also influencing the DSI are the T (trees) and AN (animals). Other sub-variables that influencing the DSI (degree of social interaction) are the VF (visit frequency), NM (no. of member brought to green space), and DIS (green space distance from home).

Based on the both SEM models, Green space Character and Social Activities are influencing DSI of its township residents. It can be seen that the evidence of cause and effect relationship between the existence of green space design properties on social affordances. This demonstrates that spatial configuration such as green space design components are the internal reason for leading to have activities. From the SEM models, it can be seen that DSI there exist evidently positive and negative effect among different activities and green space character.

\subsection{Conclusion}

In conclusion, this study had confirmed that green space design characteristics of physical and natural characters are affecting level of social interaction among new township residents in Malaysia. Those green space design characteristics such as fields and open space; playgrounds; play courts; pathway; shelters and seats can bring people together in one space. However, a well facilitated green space does not guarantee people visits. In fact, design characteristics and green space settings go hand in hand in producing successful green space. By considering the green space settings such as its maturity and shadiness; full facility; attractive; safe; clean; and proximity to home too can increase the users' visit frequency. Moreover, green space usages were depending too on the function of the spatial elements and space configuration rather than aesthetic values (i.e. lawn is utilized as a picnic area by large family to enjoy picturesque view whereas as a football field for adolescents). Therefore, neighborhood green spaces in residential community are a setting that affords social interactions for urban dwellers.

\section{Acknowledgements}

This research is funded by Fundamental Research Grant Scheme (Vot 78705) from Ministry of Higher Education, Malaysia. 


\section{References}

Abada, T., Hou, F., \& Ram, B. (2007). Racially mixed neighborhoods, perceived neighborhood social cohesion, and adolescent health in Canada. Social Science \& Medicine, 65(10), 2004-17. doi:10.1016/j. socscimed.2007.06.030.

Arbuckle, J. L. (2010). IBM SPSS Amos 19 User's Guide (pp. 1-654).Amos Development Corporation.

Bell, J. F., Wilson, J. S., \& Liu, G. C. (2008). Neighborhood greenness and 2-year changes in body mass index of children and youth. Americanjournalofpreventivemedicine,35(6),547-53.doi:10.1016/j. amepre.2008.07.006.

Bell, S., Montarzino, A., \& Travlou, P. (2007). Mapping research priorities for green and public urban space in the UK. Urban Forestry \& Urban Greening, 6, 103-115. doi:10.1016/j.ufug.2007.03.005.

Byrne, B. M. (2010). Structural Equation Modeling with AMOS (Second Edi., pp. 1-361). Taylor \& Francis Group.

Dempsey, N., Brown, C., \& Bramley, G. (2012). The key to sustainable urban development in UK cities? The influence of density on social sustainability. Progress in Planning, 77(3), 89-141. doi:10.1016/j. progress.2012.01.001.

Golicnik, B., \& Ward Thompson, C. (2010). Emerging relationships between design and use of urban park spaces. Landscape and Urban Planning, 94(1), 38-53. doi:10.1016/j.landurbplan.2009.07.016.

James, P., Tzoulas, K., Adams, M. D., Barber, A., Box, J., Breuste, J., Elmqvist, T., et al. (2009). Towards an integrated understanding of green space in the European built environment. Urban Forestry \& Urban Greening, 8(2), 65-75. doi:10.1016/j.ufug.2009.02.001.

Jorgensen, A., \& Anthopoulou, A. (2007). Enjoyment and fear in urban woodlands - Does age make a difference? Urban Forestry \& Urban Greening, 6(4), 267-278. doi:10.1016/j.ufug.2007.05.004.

Lawson, B. (2001). The Language of Space. (A. Press, Ed.). Oxford.

Lofland, L. H. (1998). In: The Public Realm: Exploring the City's Quintessential Social Territory. New York: Aldine de Gruyter.

Mahasin, M., \& V Diez Roux, A. (2010). Neighborhood Factors in Health. Neighborhood Factors in Health (pp. 341354). doi:10.1007/978-0-387-09488-5.

Moore, S. (2003). The use of public parks in England. Sport England, Countryside Agency and English Heritage.

Nurzuliza, J. (2012). How Urban Green Space Design Affects Urban Residents' Social Interaction. 7th Singapore Graduate Forum on Southeast Asia Studies 2012 (Vol. 2012, pp. 1-13). Johor Bahru, Malaysia: Asia Research Institute, National University of Singapore.

Nurzuliza, J., Ismail, S., \& Mohd Hisyam, R. (2010). Urban Green Space as Part of Ecological Corridor as Medium to Stimulates Social Cohesion among Diverse Culture in Malaysia. The 4th South East Asian Technical Universities Consortium (pp. 1-4). Malaysia.

Peters, K., Elands, B., \&Buijs, A. (2010). Socialinteractionsin urban parks: Stimulating social cohesion? Urban Forestry \&Urban Greening, 9(2), 93-100. doi:10.1016/j.ufug.2009.11.003.

Thiel, P. (1997). People, Paths and Purposes: Notations for a Participatory Envirotec-ture. (U. of W. Press, Ed.). Seattle. 
Rasidi, M.H., et.al. / Asian Journal of Environment-Behaviour Studies (ajE-Bs), 3(8) May / Jun 2018 (p.79-88)

Tzoulas, K., Korpela, K., Venn, S., Yli-Pelkonen, V., Kazmierczak, A., Niemela, J., \& James, P. (2007). Promoting ecosystem and human health in urban areas using Green Infrastructure: A literature review. Landscape and Urban Planning, 81(3), 167-178. doi:10.1016/j. landurbplan.2007.02.001. 